\title{
The Value of Life and Safety: a Survey of Recent Developments*
}

\author{
by Michael W. Jones-Lee**
}

\section{Introduction}

At the time at which The Value of Life: An Economic Analysis ${ }^{1}$ was written I believe it is fair to say that the subject matter of the book was regarded as being, at worst, in poor taste and, at best, something in the nature of a rather bizarre curiosum. To some extent this is still true Sen and Williams, in the introduction to their recent collection of essays on utilitarianism, refer to the "vulgarity" of applying cost-benefit analysis to projects that affect the safety of human life. ${ }^{2}$ Nonetheless, I do detect a substantially increased willingness to acknowledge the potential importance of systematic economic analysis of safety in public sector project appraisal and the preparedness on the part of at least some public sector decision makers to consider the possibility of adopting the kind of approach that $I$ and others have advocated.

I am not entirely sure why this change of attitude has occured. Maybe it reflects a kind of osmotic seepage in relation to new ideas or possibly it has more to do with increased public awareness of the risks associated with advancing technological change and, in particular, growing concern about nuclear power generation and waste disposal. Whatever the reason, the subject has commanded increasing interest in recent years and this would seem to be an opportune moment at which to take stock of developments during the last decade.

What do we now know about the value of life and safety that we did not know ten years ago? First, there have been significant theoretical advances so that we have a somewhat more extensive understanding of the way in which a "rational" economic agent would value safety improvements. Second, we now have access to rather more empirical information concerning individual valuation of, and attitudes to safety. Third, and perhaps most significant, the theoretical and philosophical foundations of the economic evaluation of safety have been

* This is a revised version of a paper presented at the TIMS XXVI International Meeting, Copenhagen, 1984. England.

** Professor of Economics, University of Newcastle upon Tyne, Newcastle upon Tyne, NEl 7RU,

' See Jones-Lee [1976].

${ }^{2}$ See Sen and Williams [1982], p. 18. 
subjected to fairly searching scrutiny and criticism from various quarters. In this paper I shall attempt to summarise each of these recent developments in turn, but first, for the sake of completeness and for the reader new to the subject, I shall give a brief outline of the contextual and historical background to the subject.

\section{The historical background}

Borrowing Sen and Williams' phraseology if not their sentiment, why should one want to do anything so "vulgar" as to place a money value on human life and safety? The reason is quite simply that among their various beneficial and harmful effects, many public sector allocative and legislative decisions tend to have an influence on safety and can therefore be expected to save (or cost) lives and avoid (or cause) injuries. If scarce resources are to be allocated efficiently and equitably then it is clearly important to ensure that all effects, including those on safety, are explicitly considered in the decision making process. Thus, if the tools of conventional welfare economics are to be employed in making allocative decisions, then money values of safety improvements - and costs of deterioration - are clearly required.

The earliest attempts to estimate such costs and values were based upon the so-called "gross" or "net" output definitions (see, for example, Dublin and Lotka [1930], Jones [1946], Reynolds [1956] or Dawson [1967, 1971]). Under the gross output approach, the cost of the premature death of an individual is defined, basically, in terms of the discounted present value of his or her future output foregone as a result of death. In the case of individuals whose services are not marketed, such as housewives, imputations are typically made for these services. Under the net output approach, the cost of premature death is defined as gross output minus the present value of the future comsumption that the victim would have enjoyed had he or she survived. Both approaches also typically take account of other "direct" economic effects of death and injury such as medical and police costs as well as material damage.

Those who have advocated the output-loss based definitions have usually been careful to stress that these definitions seek only to reflect the direct economic impact of premature death or injury and in no sense take account of wider human consequences. In short, it is clear that the gross output approach restricts attention to effects on G.N.P. or related output measures, while the net output approach concerns itself exclusively with direct economic effects on the rest of society. ${ }^{3}$ It is this latter point that has made so many people particularly uncomfortable about the net output approach in that, strictly applied, it would count the death of anyone past retirement age as a gain to the rest of society - a conclusion few people would find acceptable.

In reaction to the relative poverty of the ethical underpinnings of the output-based approaches, Drèze [1962], Schelling [1968], Jones-Lee [1969] and Mishan [1971] separately, and in rather different ways, advocated a radically different approach to the definition of the costs of injury and death and, more significantly, the value of their avoidance. This alternative way of defining costs and values, which has come to be known as the "willingness-to-pay"

\footnotetext{
${ }^{3}$ When an individual - who would have produced $Y$ and consumed $C$ over his remaining lifetime dies prematurely then the direct economic costs incurred by the rest of society comprise $\mathrm{Y}-\mathrm{C}$ together with any medical, police and damage costs associated with his death.
} 
approach, is firmly rooted in the principles of ex-ante Paretian welfare economics and the related precepts of conventional social cost-benefit analysis. Essentially, these prescribe (a) that public sector allocative decisions should take account of individual preferences as these exist at the time of the decision and (b) that individual preferences - and more particularly strength of preferences - are most effectively measured by the amount that individuals would be willing to pay to effect desirable outcomes or would require as compensation for undesirable ones.

This approach therefore focuses upon the amount that individuals would be willing to pay, or would require in compensation, for variations in safety that will result if a particular public sector project is undertaken. The major advantage of the approach, according to its advocates, lies in the fact that an individual's willingness to pay for safety improvement will presumably reflect his aversion to all of the adverse consequences of death or injury, including the humanitarian effects that the gross or net output approaches so obviously fail to capture.

A point of some importance for the willingness-to-pay approach is that the variations in safety afforded by public sector projects will typically take the form of very small changes in the probability of death or injury for any one individual during a forthcoming period, so that willingness tp pay or required compensation can be well-approximated by the product of the probability change and the relevant individual marginal rate of substitution of wealth for survival probability (or probability of avoidance of injury). ${ }^{4}$ Not surprisingly, therefore, early (and indeed more recent) research efforts have tended to concentrate upon the properties of these marginal rates of substitution. Fairly early on it was established that under a wide range of conditions on preferences and attitudes to risk, an individual who is "rational" in the sense required by the Von Neumann-Morgenstern or Savage axioms ${ }^{5}$ (and hence behaves as an "expected utility maximiser") will have a marginal rate of substitution of wealth for survival probability that increases with wealth and (under somewhat less general conditions) decreases with the existing level of this probability. It was also shown that concern for surviving dependents, and hence propensity to hold life insurance, plays a significant if somewhat indirect rôle in determining the magnitude of these rates of substitution.

In more general terms it was also established that conventional financial risk-aversion in the form of concavity of the utility of wealth function is sufficient to ensure that willingness to pay is an increasing and strictly concave function of survival probability. ${ }^{6}$ (The marginal rate of substitution referred to above is of course the derivative of this function evaluated at the existing level of probability.)

\footnotetext{
${ }^{4}$ An individual's marginal rate of substitution of wealth for survival probability is the modulus of the rate at which the individual is willing to trade off wealth for survival probability at the current levels of wealth and probability. Thus, if an individual would be willing to pay at most $\delta w(>0)$ to effect a small increase $\delta \pi(>0)$ in the probability of surviving a coming period then his marginal rate of substitution is (approximately) $\delta w \div \delta \pi(>0)$.

${ }^{5}$ See Von Neumann and Morgenstern [1947] and Savage [1954].

${ }^{6}$ While concavity of the utility of wealth function is a sufficient condition, it is by no means necessary. In fact for the case in which expected utility can be written as $E(u)=\pi u(w)$ where $\pi$ denotes survival probability and $u(w)$ is the utility of wealth, it can be shown that provided $u^{\prime}(w)>0$ then the necessary and sufficient condition for willingness to pay to be an everywhere increasing and strictly concave function of survival probability is that $[u(w)]^{-1}$ should be strictly convex. Thus, for example, this condition would be met even if $u(w)=\mathrm{e}^{w}$ but would not if $u(w)=\mathrm{e}^{w^{2}}$.
} 
On the empirical front, quantitative estimates of individual marginal rates of substitution of wealth for survival probability during a forthcoming period were obtained by two quite distinct methods. The first, which has been referred to as the "revealed preference" approach employs observations of the rates at which individuals actually do trade off income for physical risk, typically in labour markets where, to paraphrase Adam Smith's famous dictum, wage rates can be expected to vary so as to compensate for the ease or hardship (including the riskiness) of a job, other things being equal. The alternative approach is to ask a sample of individuals more or less directly how much each would be willing to pay or would require in compensation for specific variations in physical risk. The advantage of the revealed preference approach is that it deals with real choices, whereas in the "questionnaire" approach the choices are a fortiori hypothetical. On the other hand, wage rates are affected by many other factors besides risk, so that it is necessary to disentangle these other effects before the relevant marginal rates of substitution can be estimated. By contrast, a carefully designed questionnaire avoids this problem. Clearly then, both approaches have their particular strengths and weaknesses and are probably best regarded as complementary rather than competing estimation procedures. As things stood in 1976, revealed preference studies had produced estimates of mean marginal rates of substitution of wealth for survival probability (inflated to 1983 prices for ease of comparison) ranging from $\$ 600,000$ (Thaler and Rossen [1973]) to $\$ 5.96 \times 10^{6}$ (Smith [1973]), while questionnaire-based studies had produced estimates ranging from \$ 72,000 (Acton [1973]) to $\$ 10,330,000$ (Jones-Lee [1976]). With regard to the questionnaire results, it should be noted that both surveys employed very small non-random samples.

So far nothing has been said about the means by which willigness to pay or requirement of compensation is to be "aggregated" over individuals to produce overall values of safety improvement or costs of deterioration in safety. The answer depends crucially upon the view that is taken concerning the appropriateness or otherwise of the existing distribution of income and wealth in society. Those of more egalitarian persuasion, for example, would argue that individual willingness to pay should be weighted to reflect the view that a $\$ 1$ gain is socially "worth" more to someone who is poor than to someone who is rich. The more usual approach, and the one adopted in conventional social cost-benefit analysis, is simply to aggregate individual willingness to pay unweighted, either on the grounds that the existing distribution of income and wealth is optimal so that the marginal social value of $\$ 1$ is equal across all individuals, or because it is held that distributional adjustments are more appropriately effected by taxes and transfers than by "tampering" with allocative decisions through the use of distributional weights.

Apart from Drèze [1962], who explicitly allowed for the possibility of unequal distributional weights, all of those who had written on the subject by 1976 had explicitly or implicitly worked within the framework of conventional social cost-benefit analysis. The approach adopted in Jones-Lee [1976] is fairly typical and proceeds as follows. Suppose that each of $n$ individuals enjoys an increase of $\frac{1}{n}$ in survival probability for a forthcoming period. This entails an expected reduction in the number of deaths during the period of precisely one and has therefore come to be referred to as the saving of one "statistical life". Under the straightforward unweighted aggregation of individual willingness to pay, the overall value of this safety improvement (i.e., the value of one statistical life) is, for $n$ large (and hence $\frac{1}{n}$ small) 
given by $\sum_{i=1}^{n} m_{i} \frac{1}{n}=\frac{1}{n} \sum_{i=1}^{n} m_{i}$ where $m_{i}$ is the $i^{\text {th }}$ individual's marginal rate of substitution of wealth for survival probability. ${ }^{7}$ Thus, the value of one statistical life is simply the mean, over the relevant population, of these marginal rates of substitution.

Strictly speaking, the argument just developed assumes that individuals are concerned only for their own safety. The conventional view is that if people are also concerned - and therefore willing to pay - for others' safety then it is necessary to add to the population mean of $m_{i}$ a sum that reflects this additional willingness to pay. ${ }^{8}$ However, as will become apparent in the next section, there is now some doubt about the appropriateness of supplementing the population mean of $m_{i}$ in this way.

Finally, if, in assessing their willingness to pay, individuals fail to take account of the direct economic effects of safety improvement (such as avoidance of damage, medical and police costs and losses of net output ${ }^{9}$ ) then it will, strictly speaking, be necessary to add a sum to the value of statistical life to reflect these other effects.

\section{Theoretical developments since 1976}

Theoretical developments since 1976 fall into a number of categories and include results concerning:

(i) The relationship between a typical individual's marginal rate of substitution of wealth for survival probability and his "human capital" (effectively, his gross output).

(ii) The way in which marginal rates of substitution vary with the existing level of risk, age, income and expenditure on life insurance.

(iii) Non-marginal variations and "maximum acceptable" increments in physical risk.

(iv) The value of statistical life before and after the occurence of some life-threatening event such as kidney failure or a heart attack.

(v) Multiperiod variations in physical risk.

(vi) Safety, population effects and economic growth.

(vii) The optimal provision of safety within the context of constrained social welfare maximisation.

(viii) Benevolence and the value of the other people's safety.

(ix) Consistency and the implications of non-uniform valuation of safety by different government departments.

(x) The relationship between optimal expenditures on information concerning physical risks, risk reduction and compensation payments for increased risk where the latter can vary across different states of the world.

\footnotetext{
${ }^{7}$ Recall that this marginal rate of substitution is being treated as the modulus of the rate at which the individual is willing to trade off wealth for survival probability.

${ }^{8}$ See, for example, Jones-Lee [1976] or Needleman [1976].

${ }^{9}$ See footnote 3 above.
} 
(xi) Variations in different risks of death.

(xii) Compensating wage differentials and the value of statistical life.

All of these results have been developed within a more or less conventional "expected utility maximisation" framework and hence presuppose the kind of rationality or "coherence" implicit in the Von Neumann-Morgenstern or Savage axioms. Broadly, the models used split into two categories. In the first, individual utility functions are defined on time-streams of consumption with physical risk reflected in uncertainty concerning length of life (e.g. Conley [1976], Arthur [1981], Bergstrom [1982], Shepard and Zeckhauser [1982]). The second approach employs conditional utility of wealth functions whose properties and arguments vary over states of the world during a forthcoming period or periods, with physical risk reflected in uncertainty concerning which state will occur (e.g. Jones-Lee [1976, 1980b], Cook and Graham [1977], Weinstein, Shepard and Pliskin [1980], Dehez and Drèze [1982], Fraser [1984], Marshall [1984]). In the simplest version of the latter class of models there are just two conditional utility of wealth functions, $u_{L}\left(w_{L}\right)$ and $u_{D}\left(w_{D}\right)$, where $u_{L}$ and $u_{D}$ denote, respectively, utility of wealth conditional on survival of, and death during a forthcoming period and $w_{L}$ and $w_{D}$ denote the corresponding conditional levels of wealth. The conditional utility of wealth approach tends to make for ease of analysis and relative simplicity of mathematical expressions but is arguably based on less fundamental hypotheses concerning preferences and attitudes to risk than those underpinning the lifetime utility of consumption approach.

\subsection{The relationship between $m_{i}$ and human capital}

It is natural to wonder whether values of safety improvement based on the willingness-topay definition would be numerically significantly different from corresponding values based on the lost output definition. Since values of statistical life are typically defined in terms of the population mean of the relevant marginal rates of substitution, $m_{i}$, and since the gross output definition is tantamount to equating the value of an individual's life with his human capital, $h_{i}$, the relationship between $m_{i}$ and $h_{i}$ for a typical individual is clearly of particular interest.

Conley [1976], Jones-Lee [1980a], Bergstrom [1982], Dehez and Drèze [1982] and Shepard and Zeckhauser [1982] have each addressed this question from a theoretical point of view and have examined, in particular, the conditions under which $m_{i}$ will exceed $h_{i}$. Though the precise conditions vary subtly from one analysis to another, reflecting detailed differences in the way the underlying models are set up, these analyses all strongly suggest that sufficient conditions for $m_{i}>h_{i}$ are very weak indeed and can be expected to be fulfilled in the vast majority of cases. These conditions are most easily summarised by considering a simple single-period model in which an individual who has access to actuarially fair life insurance and annuity contracts may either survive the period with probability $\pi_{i}$ and consume an amount $c_{i}$ or die during the period with probability $1-\pi_{i}$. Given the two degrees of freedom associated with utility functions in this context, we may set the utility of dying at zero, ${ }^{10}$ so that expected utility is given by

\footnotetext{
${ }^{10}$ It might be supposed that the utility of dying would be minus infinity. However, utility functions of the type under consideration are of necessity bounded both above and below. See, for example, Arrow [1981] pp. 63-69. It should also be noted that setting the utility of dying equal to zero necessarily makes this utility independent of wealth which in turn rules out the possibility that the individual may be concerned for the well-being of surviving dependents. It is in this sense that we are dealing with a highly simplified model.
} 
$\pi_{i} u_{i}\left(c_{i}\right)$ where $u_{i}\left(c_{i}\right)$ is the individual's utility of surviving and consuming $c_{i}$. It then turns out that:

$$
\left(u_{i}^{\prime}\left(c_{i}\right)>0, u_{i}^{\prime \prime}\left(c_{i}\right)<0, u_{i}(0) \geqslant 0\right) \Rightarrow m_{i}>h_{i}
$$

and

$$
\left(u_{i}^{\prime}\left(c_{i}\right)>0, u_{i}^{\prime \prime}\left(c_{i}\right)<0, u_{i}(0)<0\right) \Rightarrow\left(\left(\exists c_{i}^{*}\right) c_{i}>c_{i}^{*} \Rightarrow \mathrm{m}_{i}>\mathrm{h}_{i}\right)
$$

The first of these results indicates that provided $u_{i}$ is strictly increasing and concave, then a sufficient condition for $m_{i}>h_{i}$ is that the individual should prefer survival with zero consumption to death. The second result indicates that if, as seems more plausible, there is some (presumably low) level of consumption below which death is preferable to survival, then there will nonetheless exist a level of consumption, $c_{i}^{*}$, above which $m_{i}>h_{i}$. Conley [1976] asserts without proof that $c_{i}^{*}$ will be below the typical value of $c_{i}$. Bergstrom [1982] provides an interesting variant on the above conditions. At the current level of $c_{i}$ and $\pi_{i}$ define a constant $k_{i}$ such that $c_{i}=\frac{k_{i}}{\pi_{i}}$. Then:

$$
\frac{d}{d \pi_{i}} \pi_{i} u_{i}\left(\frac{k_{i}}{\pi_{i}}\right)>0 \Leftrightarrow m_{i}>h_{i}
$$

Thus, a necessary and sufficient condition for $m_{i}>h_{i}$ is that an increase $\delta \pi_{i}$ in survival probability would more than compensate for a decrease

$$
\frac{k_{i}}{\pi_{i}}-\frac{k_{i}}{\pi_{i}+\delta \pi_{i}}=\frac{c_{i} \delta \pi_{i}}{\pi_{i}+\delta \pi_{i}}\left(\approx c_{i} \delta \pi_{i} \text { for } \pi_{i} \approx 1\right) \text { in consumption. In contrast to Conley's }
$$

assertion, it seems altogether more plausible to suppose that Bergstrom's condition will be fulfilled for all but those in a state of abject poverty.

\subsection{The relationship between $m_{i}$, current risk, life insurance expenditures, income and age}

Apart from its intrinsic interest, information concerning these relationships has obvious relevance for an assessment of the way in which values of statistical life will vary between subgroups in society that differ in terms of current exposure to physical risk, income, age etc. These questions have been addressed by a number of authors (see, for example, Jones-lee [1978], Arthur [1981], Dehez and Drèze [1982], Linnerooth [1982] and Shepard and Zeckhauser [1982]).

Both intuition and earlier analysis (see, for example, Raiffa [1969], Jones-Lee [1976] or Weinstein, Shepard and Pliskin [1980]) suggest that $m_{i}$ will be an unambiguously decreasing function of $\pi_{i}$, where (as in the previous section and throughout this survey) the latter denotes the $i^{\text {th }}$ individual's survival probability for a forthcoming period. However, as Dehez and Drèze [1982] demonstrate, matters turn out to be rather less clearcut and the relationship depends ultimately on the nature and terms of life insurance and annuity contracts available to the individual. Basically, the relationship between $m_{i}$ and $\pi_{i}$ hinges on two questions: 
(a) how is expected lifetime utility affected by variations in $\pi_{f}$ and (b) to what extent does $m_{i}$ reflect willingness to pay for improved terms of life insurance and worsened terms of annuity contracts as well as for improved survival prospects per se? If the individual does not hold life insurance or annuity contracts and the marginal utility of wealth conditional on survival exceeds the corresponding marginal utility conditional on death, then $m_{i}$ will, as suggested by intuition, decrease with $\pi_{i}$, essentially because the expected marginal utility of wealth increases with $\pi_{i}$. Clearly, the opposite is true, and $m_{i}$ increases with $\pi_{i}$, if the relationship between the conditional marginal utilities is reversed. If, by contrast, the individual does hold life insurance or annuity contracts but the terms of the latter do not vary with changes in $\pi_{i}$ then the outcome depends crucially upon whether or not the insurance and annuity contracts are initially actuarially fair. If such contracts are initially fair, then $m_{i}$ is independent of $\pi_{i}$ because, with optimal holdings of insurance or annuities, marginal utilities of wealth are equalised across survival and death states so that expected marginal utility is independent of $m_{i}$. Correspondingly, if insurance and annuities are less than (more than) fair then $m_{i}$ increases (decreases) with $\pi_{i}$. Finally consider the case in which the terms of insurance and annuity contracts vary with $\pi_{i}$ so as, in particular, to maintain actuarial fairness. In this case one must take account not only of the tendency of insurance and annuities to equalise conditional marginal utilities, but also of the fact that an increase in $\pi_{i}$ will affect the terms on which such contracts can be purchased and will also increase expected lifetime earnings so that $m_{i}$ will reflect an additional willingness to pay for these effects. Under such circumstances, $m_{i}$ turns out somewhat counterintuitively to be an increasing function of $\pi_{i}$. Turning to the relationship between $m_{i}$ and income or wealth, not surprisingly, none of the theoretical work during the last decade has cast doubt upon the early established proposition (see, for example, Jones-Lee [1976]) that safety is a normal good so that $m_{i}$ increases with $y_{i}$ and $w_{i}$ where the latter denote the $i^{\text {th }}$ individual's income and wealth respectively. However, some more recent analyses have shed rather more light upon the quantitative nature of this relationship for various different classes of underlying utility function. For example, Jones-Lee [1980] considers an individual with an additive-separable utility function in wealth $w_{i}$ (including discounted lifetime earnings) and time of death, $\tau_{i}$, such that $U_{i}\left(w_{i}, \tau_{i}\right)=u_{i}\left(w_{i}\right)+i{ }_{i}\left(\tau_{i}\right)$. Given perfect insurance and annuities markets, this individual will arrange for $w_{i}$ to be independent of $\tau_{i}$ (i.e. will fully cover his human capital with life insurance) and $m_{i}$ is given by:

$$
m_{i}=\frac{E f_{i}-\ell_{i}^{\prime}(1)}{\pi_{i} \mathrm{u}_{i}^{\prime}\left(w_{i}\right)}
$$

where $E /$ is the expectation of $/_{i}$ taken over all $\tau$. Differentiating with respect to $w_{i}$ and rearranging gives:

$$
\frac{\partial m_{i}}{\partial w_{i}}=\frac{-m_{i}}{w_{i}} w_{i} \frac{u^{\prime \prime}\left(w_{i}\right)}{u^{\prime}\left(w_{i}\right)}
$$

or, interpreting ${ }^{-w_{i}} \frac{u^{\prime \prime}\left(w_{i}\right)}{u^{\prime}\left(w_{i}\right)}$ as the individual's Pratt-Arrow coefficient of relative risk aversion $R R_{i}$, 


$$
\frac{w_{i}}{m_{i}} \frac{\partial m_{i}}{\partial w_{i}}=R R_{i}
$$

That is, the elasticity of $m_{i}$ with respect to $w_{i}$ for this class of utility function is given simply by $R R_{i}$.

Shepard and Zeckhauser [1982] show that for an individual who has access to perfect insurance and annuities markets and maximises the expectation of multiperiod utility of consumption, with constant proportional risk aversion for the period utility of consumption function, $m_{i}$ will be proportional to discounted future earnings so that the elasticity referred to above is equal to one.

Finally, consider the manner in which $m_{i}$ varies with age. The precise nature of the predicted relationship clearly depends on the detailed properties of underlying functions and other parameters of the models employed. However, under rather plausible assumptions concerning preferences (constant proportional risk aversion for the period utility of consumption function) Shepard and Zeckhauser [1982] show that with no life insurance and annuity markets, $m_{i}$ will follow a pronounced "inverted $u$ " life cycle peaking at about age 40 and falling by about $50 \%$ by age 60 while with perfect markets the relationship is much flatter in early years of adulthood though there is a marked decline thereafter. Arthur's [1981] analysis, developed within a rather different type of model that takes account of birth rates and population effects, predicts a steadily decreasing relationship, with $m_{i}$ falling by roughly $50 \%$ between the ages of 20 and 50.

\subsection{Maximum acceptable increments in physical risk}

An individual's marginal rate of substitution of wealth for physical risk tells us only what the individual would be willing to pay, or would require in compensation, for "small" variations in current period survival probability from the existing level, $\pi_{i}$. If we consider in particular, large reductions in survival probability then it seems clear that, for most people, required compensation will become unbounded well before survival probability is reduced to zero. If the reader doubts this, then he should ask himself whether any sum, however large, would induce him to play one round of Russian Roulette with one bullet in a six-chamber revolver. If the answer is "no" then his compensation has become unbounded before his survival probability falls to $\pi_{i}-\frac{1}{6}$. Suppose that required compensation becomes unbounded when survival probability equals $\pi_{i}-\Delta \pi_{i}^{*}$. It is then natural to refer to $\Delta \pi_{i}^{*}$ as the $i^{\text {th }}$ individual's "maximum acceptable increase in physical risk". Properties of $\Delta \pi_{i}^{*}$ and its relationship to, in particular, $m_{i}$ have obvious potential relevance for the setting of safety standards in, for example, nuclear power generation and waste disposal or other activities involving non-marginal changes in physical risk.

The properties of $\Delta \pi_{i}^{*}$ for the typical individual have been considered from a theoretical point of view in Jones-Lee [1980, 1981] and in Jones-Lee and Poncelet [1982]. These analyses assume the maximisation of the expectation of a utility function whose arguments are current wealth (including human capital), $w_{i}$, and time of death, $\tau_{i}$. In general it is shown that provided this utility function is well-behaved and in particular that it is bounded above with respect to $w_{i}$ for all $\tau_{i}$, then there will exist an inverse proportionality relationship between $m_{i}$ and $\Delta \pi_{i}^{*}$ taking the particular form: 


$$
m_{i} \Delta \pi_{i}^{*} R L_{i}=k_{i}
$$

where $R L_{i}$ is a measure of financial risk aversion that reflects the win-loss probability ratio at which an individual would just be willing to undertake a small stake, large prize financial gamble. ${ }^{\mathrm{I}}$ In general the magnitude of $k_{i}(>0)$ depends upon the precise properties of the utility function, but in the particular case in which the function takes the separable form, $U_{i}\left(w_{i}, \tau_{i}\right)=u_{i}\left(w_{i}\right)+\ell_{i}\left(\tau_{i}\right)$, it turns out that $k_{i}$ is exactly equal to one.

Given that separability of $U_{i}\left(w_{i}, \tau_{i}\right)$ implies that the individual will arrange for full coverage of human capital with actuarially fair life insurance and given that this degree of cover may not be an unreasonable approximation for many middle-income individuals with occupational pensions and insured mortgages, the approximate relationship:

$$
m_{i} \Delta \pi_{i}^{*} R L_{i} \approx 1
$$

will probably hold for a not insignificant proportion of people. If it does, then it allows a number of interesting inferences to be drawn. For example, it has been shown ${ }^{12}$ that with the arguments of relevant utility of wealth functions defined to include human capital, $R L_{i} \leqslant \frac{R R_{i}}{w_{i}}$ when $R R_{i}$ is the Pratt-Arrow measure of relative risk aversion which has been estimated to take on values typically less than 10 . Even if we set $R R_{i}=10$, equation 8 gives $m_{i} \geqslant \frac{w_{i}}{10 \Delta \pi_{i}^{*}}$. Since it seems extremely unlikely that for most people $\Delta \pi_{i}^{*}$ will be as large as $10^{-1}$ and will probably be less than $10^{-2}$, we can conclude with considerable confidence that for anyone whose preferences and attitudes to risk are reasonably approximated by the additive separable form of $U\left(w_{i}, \tau_{i}\right), m_{i}$ will almost certainly exceed human capital and will probably do so by a factor of more than 10 .

\subsection{The value of statistical life before and after the occurrence of a life-threatening event}

One of the more difficult decisions faced by those responsible for expending limited medical care budgets concerns the appropriate balance to be struck between preventive and curative medicine. In making such decisions it would clearly be valuable to have some idea about how individuals themselves regard small reductions from initially low levels of risk in relation to large reductions from initially high levels where, in particular, the number of statistical lives saved is the same in both cases.

Thus, suppose that $n$ people each face a probability $p$ of catching a disease which, if contracted, would involve a conditional probability $q$ of death. A completely effective preventive measure would therefore avoid $n p q$ statistical deaths. Now consider $m=n p$ people who have in fact contracted the disease. A completely effective cure would then also avoid $m q=n p q$ statistical deaths. How would the $n$ people's aggregate willingness to pay, $V_{1}$, for the preventive

\footnotetext{
$\left[u_{i}\left(w_{i}\right)\right]$.

${ }^{\mathrm{W}}$ Specifically, $R L_{i}$ is defined as $\frac{u_{i}^{\prime}\left(w_{i}\right)}{u_{i}^{*}-u_{i}\left(w_{i}\right)}$ where $u_{i}$ is the utility of wealth and $u_{i}^{*}$ denotes sup
( $\left.\left.w_{i}\right)\right]$.

${ }^{12}$ See Jones-Lee [1980].
} 
measure compare with the victims' aggregate willingness to pay, $V_{2}$, for the cure after contracting the disease? The answer to this question, along with the relative costs of prevention and cure, is clearly of direct relevance to a decision concerning whether to devote scarce resources to the preventive measure or to its curative counterpart.

Weinstein, Shepard and Pliskin [1980] address precisely this kind of question and using a variant of the model developed in Jones-Lee [1976] show that, ceteris paribus, $V_{2}>V_{1}$ if individuals are risk-neutral or risk-seeking with respect to wealth, while the relationship is indeterminate if they are risk-averse. Clearly $V_{1}$ and $V_{2}$ are aggregate compensating variations (or "buying prices") for safety improvement. Weinstein, Shepard and Pliskin also consider the corresponding equivalent variations (or "selling prices"), $E_{1}$ and $E_{2}$, and show that for risk-neutral or risk-averse individuals $E_{2}>E_{1}$, whereas for risk-seeking individuals the relationship is indeterminate. On the basis of these results Weinstein, Shepard and Pliskin conclude that the victims' value of statistical life after the occurrence of a life-threatening event will generally exceed the value of statistical life for all those at risk before its occurrence. ${ }^{13}$ However, one is bound to question the robustness of this conclusion, especially in view of the indeterminacy of the relationship between $V_{1}$ and $V_{2}$ for risk-averse individuals. In fact, it seems probable that for large values of $q$ (the probability of death conditional on occurrence of the life-threatening event) $V_{2}$ would be less than $V_{1}$ for individuals who are risk-averse. For example, consider the

extreme case in which $p=\frac{1}{n}$ and $q=1 . V_{1}$ is then $n$ people's aggregate willingness to pay to avoid one statistical death, while $V_{2}$ is one person's willingness to pay to avoid the certainty of death. While most people would no doubt pay a very considerable sum to avoid certain death, the amount would be bounded above by the person's ability to pay which in turn presumably cannot exceed his or her human capital. The results discussed in Section 3.1. then suggest that $V_{1}$ would substantially exceed $V_{2}$ under such circumstances.

\subsection{Multiperiod variations in physical risk}

Few public sector projects will affect safety for just one future period (e.g. the coming year): more typically, safety effects can be expected to extend over a number of periods. While Jones-Lee [1976] gives results concerning individual valuation of variations in life expectancy which have some relevance for the multiperiod risk change problem, the usefulness of these results is limited by the fact that a unit variation in life expectancy is consistent with an indefinitely large number of different ways of perturbing the mortality schedule. Clearly, a preliminary requirement for a more satisfactory analysis of multiperiod variations in physical risk is information concerning the properties of marginal rates of substitution of current wealth for survival probability during the $t^{t h}$ future period, $t=1,2, \ldots$. Results concerning these marginal rates of substitution are derived in Usher [1973], Bergstrom [1982], Jones-Lee and Poncelet [1982] and Needleman [1982]. Basically, these analyses show that the marginal rate of substitution, $m_{i t}$, of current wealth for survival probability $t$ periods hence (conditional on surviving the preceding $t-1$ periods) depends crucially upon the contribution to expected lifetime utility of survival past the $t^{t h}$ period. Since the latter can be expected to fall as $t$ increases, there will therefore be a not surprising tendency for $m_{i t}$ to decrease with $t$.

\footnotetext{
${ }^{13}$ Weinstein, She pard and Pliskin refer to the former as the value of statistical life "ex ante" the event and the latter as the value "ex post". I have avoided the use of this terminology in view of the possibility of confusion with the rather different and more common usage in this context discussed below in Section 4 .
} 
Now consider a perturbation in the mortality schedule that entails variations $\delta \pi_{i 1}, \delta \pi_{i 2}, \ldots$, $\delta \pi_{i T}$ in the conditional ${ }^{14}$ survival probabilities in each of $T$ future periods. Provided that the $\delta \pi_{i t}$ are small, then we can write the individual's compensating variation, $\delta v_{i}$, for this perturbation as:

$$
\delta v_{i}=\sum_{t=1}^{T} m_{i t} \delta \pi_{i t}
$$

Clearly, $\delta v_{i}$ depends, inter alia, on the nature of the mortality schedule and on the $\delta \pi_{i t}$. Jones-Lee and Poncelet [1982] consider the highly simplified case in which all $\pi_{t r}$ are equal (i.e., time of death is geometrically distributed) and $\delta \pi_{i 1}=\delta \pi_{i 2}=\ldots=\delta \pi_{i}$ (i.e., a safety improvement that increases the probability of surviving the $t^{\text {th }}$ period - conditional on surviving the preceding $t-1$ periods - by an equal amount for each and every future period).

$\lim _{\delta \pi_{i} \rightarrow 0} \frac{\delta v_{i}}{\delta \pi_{i}}$ then gives the individual's marginal rate of substitution, $M_{i}$, of current wealth for multiperiod physical risk. Denoting the individual's current remaining life expectancy by $E_{i}(t)$, it turns out that

$\frac{M_{i}}{m_{i 1}} \gtreqless E_{i}(t)$ as lifetime utility is an increasing convex, linear or concave function of $t$. Since it seems likely that concavity of the latter function will be the norm, then $M_{i}$ will typically be somewhat less than remaining life expectancy times $m_{i 1}$. Empirical results given in Needleman [1982] tend to confirm this, implying a value of $\frac{M_{i}}{m_{i 1}}$ of roughly 8 .

\subsection{Safety, population effects and economic growth}

Clearly, variations in safety will affect not only the survival prospects of those already alive, but will also have longer-term implications for the growth of a society's future population and hence its overall economic growth. The only theoretical analysis so far developed that takes account of these effects is Arthur [1981]. Arthur employs a neoclassical framework involving a constant returns production function, and constant age-specific mortality and fatality rates. In addition, the economy is assumed to be in a Solow-type steady state in which the growth rate of the economy equals the (constant) population growth rate and all per capita variables are constant. The consumption of those outside labour participation ages is supported by intergenerational transfer from those who are currently productive and consumption is patterned so that its discounted marginal utility is the same at all ages. Within this framework Arthur shows that the loss of social welfare due to a perturbation in the mortality schedule entailing the loss of one addititonal life at age $t$ comprises: the value of remaining expected years of life at age $t$, remaining expected labour years at age $t$, and remaining expected reproduction minus expected future consumption. Arthur then generates illustrative numerical estimates of the consumption equivalent of this loss of social welfare for various values of $t$ for the case in which the utility function displays constant elasticity of consumption. Essentially, it transpires (as noted above) that the consumption equivalent of the welfare loss decreases fairly rapidly with age. periods.

${ }^{14} \pi_{i t}$ is the probability of surviving the $t^{t h}$ period conditional upon having survived the preceding $t-1$ 


\subsection{Constrained social welfare maximisation}

As noted in Section 1, the result that the value of statistical life is given by the population mean of $m_{i}$ has typically been established within the framework of a conventional social costbenefit analysis (see, for example, Jones-Lee [1976]). Given the inherent limitations of the hypothetical compensation test that underpins cost-benefit analysis, there is clearly a case to be made for examining the question of the value of safety within the more general and robust context of maximisation of a social welfare function subject to a resource constraint. Analyses of this type have been developed in Bergstrom [1982] and Dehez and Drèze [1982]. In the latter, social welfare is a weighted sum of individual expected utilities (the weights reflecting particular interpersonal utility comparisons), safety is publicly provided and is financed by taxes levied on individuals. Tax payments are "lump sum" in that they are allowed to vary from individual to individual and are not, in particular, related to income or wealth. Finally, it is assumed that the terms of life insurance contracts do not vary with changes in individual safety. Under these circumstances, constrained maximisation of social welfare entails the following condition:

$$
c=\frac{1}{n} \stackrel{\sim}{i} m_{i}+n c \operatorname{cov}\left(m_{i}, \frac{\partial \pi_{i}}{\partial z}\right)
$$

where $c$ is the marginal cost of avoiding one additional statistical death and $z$ is overall public expenditure on safety. Bergstrom obtains a similar result.

Thus if, as seems reasonable, it is assumed that $m_{i}$ and $\frac{\partial \pi_{i}}{\partial z}$ are uncorrelated across individuals, then constrained welfare maximisation requires that public expenditure on safety should be undertaken up to the point at which the marginal cost of avoiding one statistical death equals the population mean of $m_{i}$. This more general formulation of the problem therefore leads to precisely the same result as that derived within the framework of conventional social cost-benefit analysis. However, as Dehez and Drèze note, the assumption of lump sum taxes plays a crucial role and leads to what is essentially a "first best" solution. For illustrative purposes, suppose instead that safety is financed by a proportional tax on wealth so that we are dealing with a rather more realistic "second best" situation. A simplified version of the social welfare maximisation problem can then be written as:

$\underset{t, z}{\operatorname{Max}} \sum_{i} \alpha_{i} \pi_{i}(z) u_{i}\left(w_{i}(1-t)\right)$, subject to $z=t \sum_{i} w_{i}$

where the $\alpha_{i}$ are distributional weights, $w_{i}$ is individual wealth, $z$ is total public expenditure on safety and $\left(V_{i}\right) \frac{\partial \pi_{i}}{\partial z}>0$.

On the assumption that $\operatorname{cov}\left(\alpha_{i} u_{i}, \frac{\partial \pi_{i}}{\partial z}\right)=0$, it can be shown that a necessary condition for constrained welfare maximisation is:

$$
c=\frac{\overline{\alpha_{i} u_{i}}}{\alpha_{i} \beta_{i} \pi_{i} u_{i}^{\prime}}
$$


where bars denote population means, $\beta_{i}=\frac{w_{i}}{\bar{w}_{i}}$, and $c$ is, as above, the marginal cost of avoiding one additional statistical death. Significantly, for the specification of individual expected utility used in this model, it follows that $m_{i}=\frac{u_{i}}{\pi_{i} u_{i}^{\prime}}$. In this case, therefore, the value of statistical life is given, not by the population mean of $m_{i}$, but is instead determined by weighted averages of the numerator and denominator of $m_{i},(i=1 \ldots n)$.

\subsection{Benevolence and the value of other people's safety}

The result that the value of statistical life is given by the population mean of $m_{i}$ is based on the assumption that people are concerned solely for their own safety. In fact, many people are also concerned for (and therefore presumably willing to pay for) improvements in the safety of others. It has therefore been argued that the value of statistical life should be augmented by a sum reflecting this additional willingness to pay (see particularly Jones-Lee [1976] and Needleman [1976]). However, Bergstrom [1982] shows that under certain circumstances addition of such a component to the value of statistical life would be invalid. Essentially, the question turns on the nature of a person's concern for other people's welfare. Consider first the case in which this concern is specific to safety - so that while $i$ would be willing to pay $\$ x$ for a particular improvement in j's survival prospects, he would not be willing to accede to j's request to buy him (j) \$x-worth of champagne instead. Under these circumstances it would appear that the Jones-Lee/Needleman prescription is valid. However if benevolence takes what Bergstrom describes as the "pure" form of concern for other people's utility then the prescription turns out to be unwarranted. The argument goes somewhat as follows. As has already been demonstrated, under "first-best" conditions, equality between the marginal cost of avoiding one statistical death and the population mean of $m_{i}$ is a necessary condition for ensuring that no-one's "selfish" expected utility can be increased without reducing anyone else's. The latter is, in turn, a necessary condition for maximising the utility of someone who displays "pure" benevolence. It therefore follows that the value of statistical life for a society displaying "pure" benevolence should be the unaugmented population mean of $m_{i}$. As Bergstrom observes, "pure" benevolence requires that at the margin a person's concern for other people's safety will be precisely balanced by his concern for the reduction in their consumption that will be required to finance the extra safety. In the end, then, it would appear that the legitimacy, or otherwise, of augmenting the value of statistical life to reflect concern for other people's wellbeing depends on the precise form that this concern takes.

\subsection{Consistency in the valuation of safety}

Suppose that a "true" value of statistical life, $V^{*}$, could be established. Abstracting from the fact that such a value would probably vary between different causes of death, it is then clear that a first-best allocation of the overall public sector budget would require that all government departments should employ $V^{*}$ in evaluating projects that affect safety. Now suppose that a particular department (say department 1 ) is convinced that $V^{*}$ is the "true" value but that other departments do not share this conviction (either because they have different views about the appropriate way to define such a value or because they have doubts about the soundness of the empirical estimation procedure from which $V^{*}$ was derived). What is then the appropriate second-best action for department 1? Should it, in particular, evaluate its own 
safety projects using $V^{*}$ as the value of statistical life or are there reasons why department 1 should employ some other value? These questions are considered in Dobbs [1985]. Dobbs first emphasises the distinction between the central government decision concerning the division of its overall public sector investment budget between different sectors or departments (e.g. health, transport, education) and the departmental cost-benefit analysis of individual projects and consequent construction of a departmental investment programme. Dobbs then introduces a simple but illuminating model of individual departmental decision-making in which the $j^{\text {th }}$ department's investment programme is characterised by just three features, namely total capital outlay, $K_{j}$; lives saved, $X_{j}$ and other net-of-outlay benefits, $A_{j}$. The range of investment opportunities open to the department is then taken to be summarised by a bivariate density function for project outlays $k_{j}\left(a_{j}, x_{j}\right)$ where $a_{j}=\frac{A_{j}}{K_{j}}, x_{j}=\frac{X_{j}}{K_{j}}$ and

$$
\int_{\alpha}^{\beta} \int_{\eta}^{\varepsilon} k_{j}\left(a_{j}, x_{j}\right) d x_{j} d a_{j}
$$

gives the total capital cost of projects having safety "returns" in the interval $[\eta, \mathcal{E}]$ and other "returns" in the interval $[\alpha, \beta]$.

Using this model Dobbs then proceeds to show that it will be appropriate for department 1 to set the value of statistical life at $V^{*}$ (the "true" value) only if either the central government has full information concerning $k_{j}\left(a_{j}, x_{j}\right)$ for all $j$ and agrees with department 1 that $V^{*}$ is the true value of statistical life or if (a) the central government decision concerning the level of departmental budgets is independent of the performance of projects within departments and (b) departmental decision-makers are concerned only with the performance of their own department's projects. Suppose, by contrast, that in allocating funds between departments, central government is influenced by the rates of return reported to it by individual departments, favouring those that are able to report higher rates of return. Under these circumstances it follows that if department 1 uses $V^{*}$ as the value of statistical life and $V^{*}$ tends to exceed the values of statistical life used by other departments then there will be an unwarranted bias in favour of department 1 and against other departments in the central government decision concerning departmental budgets. In this case the appropriate second-best policy would be for department 1 to use a value of statistical life somewhat lower than $V^{*}$. Alternatively, suppose that the central government decision concerning the level of departmental budgets is independent of the performance of projects within departments but that departmental decision makers are concerned with the overall performance of public sector projects rather than solely with their own department's projects. It is then clear that even with disagreement about the appropriate value for statistical life, there are potential gains to decision makers from moving towards some compromise "middle" value, ${ }^{15}$ though as Dobbs points out, the precise nature of the appropriate compromise will depend upon the extent of information concerning $k_{j}\left(a_{j}, x_{j}\right), j=1 \ldots n$, available to decision makers in each of the $n$ departments. Nonetheless, it again follows that it will generally not be appropriate for department 1 to use $V^{*}$ as the value of statistical life.

${ }^{5}$ For a development of this kind of argument, see for example Sugden and Williams [1978], pp. $187-190$. 


\subsection{Information and state-dependent compensation}

If a government is actually going to compensate individuals for increases in physical risk due to public sector projects then it is natural to wonder what properties an optimal compensation structure would possess. The answer to this question is clearly inextricably bound up with the nature of optimal safety expenditure by the government and also, to the extent that government and individual perceptions of risk differ, with optimal government expenditure on the dissemination of information concerning risk.

In order to shed light on this matter, Fraser [1984] considers a situation in which:

(a) The government actually does make compensation payments to individuals when it introduces projects that increase physical risk;

(b) Compensation payments can be state-dependent in the sense that the sum paid conditional on the occurrence of death or injury during a given period may differ from the sum paid conditional on non-occurrence;

(c) The government's objective is to minimise expected compensation payments subject to the condition that individual expected utility "with" a project that increases risk is no lower than without it; and

(d) Individual and government assessements of the probability of death or injury are not necessarily equal and are endogenous in the sense that they are capable of being influenced by government expenditures on information and/or risk-reducing activities.

Within the context of a simple single-period model and on fairly plausible assumptions about the properties of utility functions and risk-perception functions, Fraser concludes that the government will tend to engage in more risk reduction expenditure or less informational expenditure with state-dependent compensation than with compensation that is state-independent. State-dependent compensation would therefore seem to have certain advantages over state-independent compensation in that it leads government to provide more of what it perceives to be beneficial for individuals, though to the extent that informational expenditures are lower, individuals themselves may not share government's view.

\section{II. Variations in different risks of death}

An implicit assumption in much of the theoretical literature on the value of life and safety is that the death of a particular individual during a given period can be treated as a single "homogeneous" event. In reality, of course, people face a wide variety of different risks of death, e.g. from car accidents, heart disease and so on. Nonetheless, provided (a) that people are indifferent between various ways of dying and (b) the events of death by different causes are mutually exclusive and (c) variation in the risk of death by one cause does not affect the risks of death by other causes, then a situation in which the $i^{\text {th }}$ individual face probabilities $p_{t j}(j=1 \ldots . m)$ of death from $m$ different causes will be equivalent to one in which he faces a single probability $p_{1}$ of death with $p_{i}=\sum_{j=1}^{m} p_{i j}$ and

$$
\left(V_{i}\right) \frac{\partial w_{i}}{\partial p_{i j}}=\frac{\partial w_{i}}{\partial p_{i}}=-\frac{\partial w_{i}}{\partial \pi_{i}}
$$

where $\pi_{1}=1-p_{t}$. 
Under these circumstances there will therefore be no ambiguity associated with the concept of the individual's marginal rate of substitution of wealth for survival probability. However, if either people are not indifferent between various ways of dying or the events of death by different causes are not mutually exclusive or variations in the risk of death by one cause affects the risks of death by other causes then matters become more complicated.

Clearly, the nature of individual attitudes to death by different causes is an essentially empirical matter so that one is unlikely to gain any significant insights from a priori theoretical analysis. However such analysis can shed some light on the relationship between different causes of death. In particular, Sussman [1984] considers the case in which the events of death by different causes are independent (rather than mutually exclusive) while maintaining the assumption that individuals are indifferent between different ways of dying and variations in the risk of one cause of death do not affect the risks of death by other causes. In this case $p_{i}=1-\prod_{j=1}^{m}\left(1-p_{i j}\right)$ so that in general:

$$
\frac{\partial w_{i}}{\partial p_{i 1}} \neq \frac{\partial w_{i}}{\partial p_{i 2}} \neq \ldots \neq \frac{\partial w_{i}}{\partial p_{i}}
$$

Thus in this case it is, strictly speaking, necessary to distinguish between the various different marginal rates of substitution of wealth for risk of death and hence various different values of statistical life even when individuals are indifferent between different ways of dying. However, it is clear that with all $p_{i j}$ small (as will be the case for most people) the distinction between mutually exclusive and independent causes of death is of only limited significance with, in particular,

$$
1-\prod_{j=1}^{m}\left(1-p_{i j}\right) \approx \sum_{j=1}^{m} p_{i j}
$$
so that it is no surprise that Sussman finds that the differences between the various $\frac{\partial w_{i}}{\partial p_{i j}}$
are less than one percent for typical orders of magnitude of the $p_{i j}$.

\subsection{Compensating wage differentials and the value of statistical life}

One of the more common approaches to estimating the value of statistical life is based upon compensating wage differentials in labour markets. Implicit in this approach is the assumption that, ceteris paribus, wage rates will adjust to compensate for differences in risk between industries and occupations so that a worker with a given level of skill will be indifferent between a "safe" job with a lower wage rate and a "risky" job with a higher wage.

In recent paper Marshall [1984] questions the legitimacy of this assumption in the context of a model in which workers (a) must choose between a safe and a risky industry, (b) have access to actuarially fair life insurance and (c) have access to actuarially fair gambles in wealth. In this model, it turns out that the choice of industry is ultimately dependent upon the outcome of gambles in wealth in that "losers" opt for the risky industry in order to augment their consumption claims with higher wage rates while "winners" are content to accept the lower wage rates in the safe industry. Furthermore, it is a feature of equilibrium in this model that the wage differential is not large enough to compensate for the difference in risk so as to equalise expected utility between the two groups of workers. Nonetheless, Marshall shows that given the availability of fair gambles and life insurance, the marginal rate of substitution of 
wealth for survival probability is equalised between the two groups of workers and is in turn equal to the wage differential divided by the difference in risk. Thus, somewhat paradoxically, it turns out that the appropriateness of using the latter as an exact measure of the value of statistical life would appear to depend not upon the fact that wage differentials compensate for risk so as to equalise expected utility but rather is a result of the availability of appropriate opportunities for financial gambles and life insurance. However, Marshall notes that even in the absence of such opportunities, the wage differential/risk difference ratio provides an approximation to the required value of statistical life, the quality of the approximation depending upon, amongst other things, the size of the difference in risk.

\section{Empirical developments since 1976}

By 1976, relatively few attempts had been made to obtain empirical estimates of the value of statistical life. More recently, however, a number of empirical studies have shed rather more light on the matter. The majority of these studies have been "revealed preference" exercises based on compensating wage differentials in labour markets, but some attempts have been made to obtain estimates by other means, notably from observations of automobile seat belt use, willingness to pay for domestic fire detectors and from house price/air pollution tradeoffs in the U.S.A. and by the "questionnaire" method in three studies for the U.K. and two for the U.S.A. In summarising these result this section draws heavily on earlier surveys of empirical work by Smith [1979] and Blomquist [1982], both of which should be consulted for more detailed discussion of the estimation procedures employed.

\subsection{Revealed preference results}

The results of revealed preference studies are summarised in chronological order inTable 1. All estimates have been converted to \$U.S. in 1983 prices for ease of comparison. As can be seen, these results split into eight estimates of the value of statistical life of less than $\$ 1,000,000$ and eight in excess of $\$ 1,000,000$, the overall mean being $\$ 2,220,000$.

It is interesting to note that the eight lower estimates include all five of those based on "non-labour market" wealth/risk or time/risk tradeoffs and two based on compensating wage differentials for workers in more risky occupations (Thaler and Rosen and Needleman). It may well be that the relatively indirect nature of the non-labour market tradeoffs and the bias in attitudes to physical risk that can be expected of workers in more risky occupations go some way towards explaining the discrepancy between the "high" and "low" estimates in Table 1. Marin and Psacharopoulos [1982] provide more subtle reasons for differences between their own and other compensating wage differential estimates.

\subsection{Questionnaire results}

The results of studies using the questionnaire approach are summarised in chronological order in Table 2. Again, all estimates have been converted to \$U.S. in 1983 prices.

While these estimates are more widely spread than the revealed preference results, it is again the case that roughly half of the estimates fall below $\$ 1,000,000$ and half above, with an overall mean of $\$ 2,350,000$. 


\section{Table 1}

Estimates of the value of statistical life from revealed preference studies (\$ U.S. 1983)

\begin{tabular}{|c|c|c|}
\hline Authors & Data Source & $\begin{array}{l}\text { Estimated Value } \\
\text { of Statistical Life }\end{array}$ \\
\hline $\begin{array}{l}\text { Thaler and Rosen } \\
\text { [1973] }\end{array}$ & $\begin{array}{l}\text { Compensating wage differentials for } \\
\text { workers in risky occupations (U.S.A.) }\end{array}$ & 600,000 \\
\hline Smith [1973] & $\begin{array}{l}\text { Compensating wage differentials } \\
\text { of males in manufacturing industries } \\
\text { (U.S.A.) }\end{array}$ & $5,960,000$ \\
\hline Melinek [1974] & $\begin{array}{l}\text { Time/safety tradeoff in use of } \\
\text { pedestrian subways (U.K.) }\end{array}$ & 520,000 \\
\hline Melinek [1974] & $\begin{array}{l}\text { Compensating wage differentials in } \\
\text { industry (U.K.) }\end{array}$ & $1,190,000$ \\
\hline $\begin{array}{l}\text { Ghosh, Lees and } \\
\text { Seal [1975] }\end{array}$ & $\begin{array}{l}\text { Motorway speed/time/fuel tradeoff } \\
\text { (U.K.) }\end{array}$ & 510,000 \\
\hline Smith [1976] & $\begin{array}{l}\text { Compensating wage differentials for } \\
\text { males in manufacturing (U.S.A.) }\end{array}$ & $3,360,000$ \\
\hline Dillingham [1978] & $\begin{array}{l}\text { Compensating wage differentials for } \\
\text { manual workers in manufacturing and } \\
\text { construction (U.S.A.) }\end{array}$ & 460,000 \\
\hline Olson [1978] & $\begin{array}{l}\text { Compensating wage differentials in } \\
\text { industry (U.S.A.) }\end{array}$ & $7,840,000$ \\
\hline Veljanovski [1978] & $\begin{array}{l}\text { Compensating wage differentials in } \\
\text { industry (U.K.) }\end{array}$ & $5,990,000$ \\
\hline Viscusi [1978] & $\begin{array}{l}\text { Compensating wage differentials for } \\
\text { manual workers (U.S.A.) }\end{array}$ & $3,410,000$ \\
\hline Blomquist [1979] & $\begin{array}{l}\text { Time/safety tradeoff in use of car } \\
\text { seat belts (U.S.A.) }\end{array}$ & 560,000 \\
\hline Brown [1980] & $\begin{array}{l}\text { Compensating wage differentials in } \\
\text { National Longitudinal Survey Young } \\
\text { Men's Sample (U.S.A.) }\end{array}$ & $1,800,000$ \\
\hline Needleman [1980] & $\begin{array}{l}\text { Compensating wage differentials for } \\
\text { construction workers (U.K.) }\end{array}$ & 170,000 \\
\hline Portney [1981] & $\begin{array}{l}\text { House price/air pollution tradeoff } \\
\text { (U.S.A.) }\end{array}$ & 220,000 \\
\hline Dardis [1982] & $\begin{array}{l}\text { Purchase of domestic smoke detectors } \\
\text { (U.S.A.) }\end{array}$ & 420,000 \\
\hline $\begin{array}{l}\text { Marin and } \\
\text { Psacharopoulos [1982] }\end{array}$ & $\begin{array}{l}\text { Compensating wage differentials for } \\
\text { manual and non-manual workers (U.K.) }\end{array}$ & $2,460,000$ \\
\hline
\end{tabular}


Clearly, there are various reasons why one would be inclined to regard some of these estimates as being a priori less reliable than others. For example Acton's survey, as well as being small and using a non-random sample, involves a safety improvement that has obvious public goods properties (provision of a neighbourhood ambulance with special facilities for heart attack victims) so that there is a strong suspicion that non-revelation effects may have produced a substantial downward bias in responses. ${ }^{16}$ The Jones-Lee [1976] estimate was also derived from a small highly-biased sample of academics, civil servants and research workers and in addition involved very small probability reductions (e.g., $2 \times 10^{-6}$ ) which may well have contributed substantially to the very high estimate of the value of statistical life. As far as Melinek's survey is concerned there are obvious doubts about the credibility of the proposal that it would be possible to produce completely safe cigarettes and in any case, this estimate is a fortiori based on the willlingness to pay of smokers and one is bound to suspect that their attitudes to physical risk are not typical. Of the remaining estimates, those of Maclean and JonesLee/Hammerton/Philips are clearly of the same order of magnitude but the Melinek/ Woolley/Baldwin figure is an embarrassing factor of ten samller than the Maclean estimate for the same source of risk reduction. Another disturbing feature of these results is the very wide spread of estimates produced within particular studies in the cases of Frankel and Mulligan. Though precise details of these studies are still awaited, it seems clear that there was a tendency for questions involving small variations in risk to produce high estimates of the value of statistical life and vice-versa, a phenomenon of which there is some evidence elsewhere in the questionnaire results.

\subsection{Other results}

Two further sets of empirical results are of interest. These concern (a) people's willingness to pay for others' safety and (b) the nature of the relationship between $m_{i}$ and income, age, etc.

Using U.S. data concerning individual's willingness to act as kidney transplant donors, Needleman [1976] estimates individual willingness to pay for the safety of all relatives as being, on average, about $45 \%$ of willingness to pay for "own" safety. Jones-Lee, Hammerton and Philips [1985] estimate the mean marginal rate of substitution of wealth for the survival probability of one car passenger (presumably, normally a close friend or relative) to be $£ 500,000$ (or $\$ 790,000$ in 1983 prices). Taken together, these results tend to suggest that as far as safety is concerned, benevolence is not "pure" in the sense proposed by Bergstrom [1982] so that it will be appropriate to supplement the value of statistical life to reflect willingness to pay for others' safety - and that the amount involved will probably be in the region of 30-50\% of the value of statistical life based on willingness to pay for "self only" risks.

One of the significant advantages of the questionnaire approach is that it facilitates empirical investigation of the relationship between individual willingness to pay for safety and income, age or other factors. Acton [1973] ran linear regressions of individual willingness to pay for specified risk reductions on income, wealth, family medical expenditure and dummies

${ }^{16}$ Though it should be noted that Acton's questionnaire was carefully worded so as to minimise the likelihood of this kind of effect. 
Table 2

Estimates of the value of statistical life from questionnaire studies (\$ U.S. 1983)

\begin{tabular}{|c|c|c|}
\hline Authors & Data Source & $\begin{array}{l}\text { Estimated Value } \\
\text { of Statistical Life }\end{array}$ \\
\hline Acton [1973] & $\begin{array}{l}\text { Small non-random }{ }^{17} \text { sample survey } \\
{[n=93] \text { of willingness to pay for public }} \\
\text { provision of prevention of death from } \\
\text { heart attack (U.S.A.) }\end{array}$ & 72,000 \\
\hline $\begin{array}{l}\text { Melinek, Woolley } \\
\text { and Baldwin [1973] }\end{array}$ & $\begin{array}{l}\text { Non-random sample survey }[n=873] \text { of } \\
\text { willingness to pay for domestic fire } \\
\text { safety (U.K.) }\end{array}$ & 330,000 \\
\hline Melinek [1974] & $\begin{array}{l}\text { Non-random sample survey }[n=873] \\
\text { of willingness to pay for hypothetical } \\
\text { safe cigarettes (U.K.) }\end{array}$ & 170,000 \\
\hline Jones-Lee [1976] & $\begin{array}{l}\text { Small non-random sample survey } \\
{[n=31] \text { of willingness to pay for air }} \\
\text { travel safety (U.K.) }\end{array}$ & $10,330,000$ \\
\hline Mulligan [1977] & $\begin{array}{l}\text { Details of sample not yet available. } \\
\text { Willingness to pay for decreased } \\
\text { risks of nuclear power plant } \\
\text { accidents (U.S.A.) }\end{array}$ & $\begin{array}{c}74,000 \\
520,000 \\
4,320,000^{18}\end{array}$ \\
\hline Maclean [1979] & $\begin{array}{l}\text { Quota sample survey from London area } \\
{[n \approx 300] \text { of willingness to pay for }} \\
\text { domestic fire safety }{ }^{19} \text { (U.K.) }\end{array}$ & $3,480,000$ \\
\hline Frankel [1979] & $\begin{array}{l}\text { Details of sample not yet available. } \\
\text { Willingness to pay for air travel } \\
\text { safety (U.S.A.) }\end{array}$ & $\begin{array}{c}69,000 \\
4,070,000^{20}\end{array}$ \\
\hline $\begin{array}{l}\text { Brown and Green } \\
\text { [1981] }\end{array}$ & $\begin{array}{l}\text { Small non-random sample survey } \\
{[n \approx 40] \text { of students' willingness to pay }} \\
\text { for car safety (U.K.) }\end{array}$ & $\begin{array}{r}\text { No estimate } \\
\text { given }\end{array}$ \\
\hline $\begin{array}{l}\text { Prescott-Clarke } \\
\text { [1982] }\end{array}$ & $\begin{array}{l}\text { Large random sample survey }[n=1,170] \\
\text { of required compensation for increased } \\
\text { job risk and willingness to pay for } \\
\text { removal of risks due to nuclear power } \\
\text { generation (U.K.) }\end{array}$ & $\begin{array}{r}\text { No estimate } \\
\text { given }\end{array}$ \\
\hline $\begin{array}{l}\text { Jones-Lee, } \\
\text { Hammerton and } \\
\text { Philips [1985] }\end{array}$ & $\begin{array}{l}\text { Large random sample survey }[n=1,150] \\
\text { of willingness to pay for transport safety } \\
\text { (U.K.) }\end{array}$ & $2,370,000$ \\
\hline
\end{tabular}

17 Though Acton describes one of his subsamples as "random" it cannot strictly speaking be regarded as such since it was drawn exclusively from the Boston metropolitan area (presumably not selected at random) and did not therefore give all individuals in the U.S.A. an equal probability of selection.

${ }^{18}$ These three estimates involved annual risk reductions of $10^{-3}, 10^{-4}$, and $10^{-5}$ respectively.

${ }^{19}$ While Maclean also asked questions concerning willingness to pay for a variety of other risk reductions, there are some doubts concerning the way in which the period of the risk reduction was employed in estimating the value of statistical life. The question and analysis of willingness to pay for domestic fire safety was, however, unambiguous.

${ }^{20}$ These two estimates involved risk reductions of $10^{-3}$ and $10^{-6}$. 
for attitudes to heart disease, health status and headship of household. While the dummies perform fairly well as explanatory variables, income and wealth are disappointingly insignificant.

By contrast, multiple regression results presented in Jones-Lee, Hammerton and Philips [1985] do yield some significant coefficients on income and suggest that the elasticity of $m_{i}$ with respect to income is probably in the region of 0.3 . This agrees with an earlier estimate given in Blomquist [1979] and confirms the theoretical prediction that safety is a normal good. As far as the effect of age is concerned, a quadratic age variable has the most consistently significant coefficient in the Jones-Lee, Hammerton and Philips study and tends to confirm Shepard and Zeckhauser's [1982] theoretical prediction of an "inverted-u" life cycle relationship. The effects of social class, previous accident experience, annual mileage and other explanatory variables are generally insignificant, suggesting that of those readily identifiable personal characteristics that might be expected to affect individual willingness to pay for safety, income and age are the most important determinants, though the very low values of $R^{2}$ in these regressions indicate that these variables explain only a small fraction of the overall variance of $m_{t}$ across individuals.

\section{Criticisms of the willingness-to-pay approach}

The most vigorous criticism of the willingness-to-pay approach to the valuation of life and safety has been developed in a series of articles and publications by John Broome [1978a, 1978b, 1982, 1983a, 1983b, 1983c]. Though the focus of Broome's attack has shifted subtly over time, the following are the central features of his overall objection to the willingness-to-pay approach.

(a) The identification of an individual's interests with his preferences and, more significantly, his choices is particularly suspect in the case of decisions affecting the safety of his life. (Many people choose to smoke but is it in their best interests to do so?)

(b) People may be rather poor judges of the nature and extent of the physical risks that they face. (How many people have a clear idea of the numerical magnitude of, say, the annual risk of death from domestic fires?)

(c) Even if they have access to identical "adequate" information concerning a particular source of physical risk, different people may nonetheless form different subjective probability judgements concerning these risks. This leads to a variety of difficulties for government decisions that respect individual preferences formed on the basis of differing subjective probabilities. (How, for example, ought the wishes of the pro- and anti-nuclear power lobbies to be weighed against each other?)

(d) The willingness-to-pay approach is essentially an application of the hypothetical compensation test to small ex ante variations in risk. However, in the event, these variations in individual risk will result in one or another ex post outcome involving the saving or loss of a particular number of lives. Should not the compensation test be applied to these various possible ex post outcomes rather than to small ex ante variations in risk? For example, suppose that if a particular project is adopted $10^{6}$ people will be exposed to independent incremental individual risks of death of $10^{-6}$ each. The willingness-to-pay approach would ask about the ex ante compensation that each individual would require in order to be induced to accept the additional risk. To the extent that the compensation required by each 
individual is finite then so too will be the aggregate compensation and the project may well be recommended in spite of its adverse impact on safety, provided that its other beneficial effects are sufficiently extensive. Alternatively, one could recognise that the actual additional number of deaths caused by the project would be given by a Poisson distribution with mean one and then apply the compensation test to each of the $10^{6}+1$ possible ex post outcomes in the distribution - no deaths, one death, two deaths etc. Broome argues that if the compensation test is to be used at all in this kind of decision then in principle it should be applied in its ex post rather than ex ante form. However, as Broome notes, one then encounters the difficulty that the test will resoundingly reject the above kind of project under each of the outcomes involving additional death - simply because for most people no sum, however large, would compensate for the certainty of death - regardless of the other possibly highly beneficial consequences of the project.

In view of his objections to the compensation test in both its ex ante and expost forms, Broome considers the possibility of adopting a utilitarian approach to social decisions that affect safety. This approach has certain attractive features in that provided social and individual choices obey the Harsanyi [1955] postulates and social and individual probability judgements coincide, then maximisation of social welfare entails maximisation of the expectation of the weighted sum of individual utilities. This in turn avoids the necessity to distinguish between the ex ante and ex post approaches to social decision making in that the expectation of the weighted sum of individual utilities is identical to the weighted sum of individual expected utilities, the former being the indicator of social welfare relevant to an ex post approach and the latter for the ex ante.

Quite apart from its very stringent requirements concerning preferences and probability judgements, the utilitarian approach suffers from a further difficulty in that if it is to be used as a practical decision making device then one requires some method of measuring individual expected utilities. The most obvious way to do so is to use individual willingness to pay or requirement of compensation but one then encounters the necessity to adjust for the marginal utility of wealth and this will depend, inter alia, upon wealth and nearness to death.

Given all of the difficulties that he perceives to be associated with the valuation of safety, particularly in terms of individual ex ante expected utility or willingness to pay, Broome suggests that ".... it will be more productive to set about valuing life itself directly, rather than safety". With this in mind, he has turned in his more recent writing (e.g. Broome [1983c] to view the problem from a more purely philosophical perspective. Amongst other things, Broome has addressed the questions of what one loses by dying and how one compares different effects on the composition and size of future populations, arguing that answers to these questions are required before one can sensibly place a value upon a particular person's life and upon the lives of those that will be born if he or she survives and will not otherwise. Not surprisingly, Broome's attempts to discover a satisfactory procedure for valuing life, as such, from a philosophical perspective have so far proved almost completely unsuccessful, though it should be said that his careful and incisive examination of the question has shed light on a variety of other important issues. ${ }^{21} \mathrm{As}$ far as public sector decisions about safety are concerned, Broome appears to have rejected completely the possibility that economists might have

\footnotetext{
${ }^{21}$ See, for example, Broome [1984a, 1984b].
} 
anything at all useful to say on the subject and instead argues that politicians, as the elected guardians of our individual interests, really should make these decisions, however difficult and uncomfortable they may be, and should not take refuge in "easy" answers provided by what Broome regards as a spurious economic calculus. ${ }^{22}$ Needless to say, Broome's critics are somewhat less sanguine about the intellectual and moral capacities of politicians in this context and indeed the prevalent view of Broome's various criticisms appears to be that while these should alert us to various potential difficulties inherent in the willingness-to-pay approach, they constitute grounds for more circumspect application of the approach rather than wholesale rejection of it, especially as Broome offers us no concrete alternative, save reliance upon political judgement.

Other criticisms of the willingness-to-pay approach are developed in Zeckhauser [1975], Atiyah [1982], Keeney [1982] and Linnerooth [1982]. Zeckhauser argues not for rejection of the willingness-to-pay approach, but rather for its careful use as one of possibly many aids to social decision making. According to Zeckhauser, individual willingness to pay for improved survival probability cannot be regarded as the definitive determinant of policy choices for a variety of reasons. First, even if aggregate willingness to pay exceeds the cost of a particular safety improvement, it will typically be impossible to arrange for taxes and transfers so as to ensure that everyone gains. A second and related point concerns the process by which such decisions are made. Zeckhauser argues that the manner in which public sector decisions affecting safety are actually taken may be every bit as important to affected individuals as the numerical magnitude of the money/risk tradeoffs involved. Other problems perceived by Zeckhauser include the effects of anxiety, the manner in which the interests of future generations are to be weighed in decisions having long term effects on safety and the way in which to take account of inequalities in the distribution of income.

Atiyah views the problem from an essentially legal perspective. His first objection to the willingness-to-pay approach is less one of principle than of practice and concerns the very high estimates of the value of statistical life produced by some recent studies (see Tables 1 and 2 above). In particular, Atiyah argues that unless court awards in cases involving death or injury are set at levels comparable with values of statistical life used in public sector allocative decisions then serious inconsistencies may emerge between private and public sector safety standards especially if, as seems probable, private sector safety decisions are influenced by the magnitude of prospective court awards in cases of alleged negligence. Atiyah seriously doubts the equity and feasibility, at least in the U.K. context, of setting court awards at the levels of the value of statistical life implied by some willingness-to-pay studies.

A second point that concerns Atiyah is the extent to which individuals may legitimately be supposed to have taken account of potential legal compensation for the negligence of others in making decisions concerning risky activities or indeed to have made such decisions in anything like a well-informed and reasoned manner.

Keeney's objections to the willingness-to-pay approach arise from the difficulty of obtaining reliable empirical estimates and from his view (similar to that expressed by Zeckhauser) that individual willingness to pay for safety - conditioned as it is by the funds available to the individual at risk - may have little relevance for the decision-making of a

${ }^{22}$ See Broome [1983a, 1983c]. 
public sector body whose budget constraint need bear little relation to the wealth of individuals who are affected by its decisions. In consequence, Keeney proposes that the problem be viewed not from the perspective of affected individuals, but directly from that of decision makers within the public sector body concerned. To this end, Keeney proposes the use of a multiattribute "organisational utility function" as a means of summarising the value judgements of the relevant decision makers.

Finally, Linnerooth's criticisms of the willingness-to-pay approach focus upon a variant of the ubiquitous problem of trading off equity and efficiency in public sector allocative decisions. If, as theory predicts (and empirical evidence confirms) willingness to pay is an increasing, strictly concave function of incremental survival probability (and, by corollary, required compensation an increasing, strictly convex function of incremental physical risk) then under the willingness-to-pay approach the cost (aggregate required compensation) of exposing a small number of people to relatively large incremental individual risks of death will exceed the cost of exposing a larger number of people to smaller risks even when expected lives lost are identical in both cases. It follows that it would be perfectly possible for scheme A - involving large incremental risks for a few people - to be regarded as worse than scheme B - involving smaller increments for more people - in spite of the fact that the expected number of lives lost under A was less than that under B. In this case "efficiency" (minimising expected number of lives lost) would be sacrificed in favour of "equity" (avoiding large incremental risks for a few people) though it should be stressed that this concept of efficiency is somewhat narrower than that of Paretian efficiency.

A related, but not identical, problem that concerns Linnerooth arises from the influence of the existing level of an individual's survival probability on his willingness to pay. As shown by Jones-Lee [1976] and Dehez and Drèze [1982], under certain circumstances $m_{i}$ will be larger the higher an individual's current exposure to physical risk. This is essentially because willingness to pay varies inversely with marginal expected lifetime utility of wealth and the latter is in turn an increasing function of survival probability. The most extreme example of this kind of phenomenon is the person who has been diagnosed as terminally ill and is, in consequence, willing to spend very large sums on possible cures with very low probabilities of success.

Thus, if social decisions concerning safety expenditure are based upon individual willingness to pay then there will be a tendency for resources to be directed towards safety improvements for people currently facing high levels of physical risk, at the expense of expected lives saved overall, so that the willingness-to-pay approach again tends to favour equity in the tradeoff with efficiency. While Linnerooth expresses some sympathy for pursuit of the equity objective per se, she doubts the appropriateness of allowing the tradeoff between equity and efficiency to be resolved by considerations of individual willingness to pay alone.

\section{Concluding comments}

In spite of the criticisms discussed in the previous section, it would appear to be the case that the willingness-to-pay approach still commands qualified support from the majority of economists interested in the subject, though few would wish to argue that willingness-to-pay based costs and values should represent the "last word" as far as public sector safety decisions are concerned. Advocacy of the use of such costs and values is typically tempered by the recommendation that they should be treated as but one of possibly many inputs to the decision making process. I believe that it is also true to say that an increasing number of public 
sector agencies are inclining to the view that the willingness-to-pay approach is, in principle, the most appropriate basis for defining costs and values currently available in this context. However, public sector agencies' resistance to wholesale rejection of the gross output approach in favour of willingness-to-pay, though detectably weakening, is still present, largely because of doubts about the reliability of empirical estimates of willingness-to-pay based values of statistical life. It is therefore to be hoped that the next decade will see substantial funds and research efforts directed towards refinement of empirical estimation procedures.

Examples of other areas to which attention could fruitfully be directed in future research are:

(a) The relationship between willingness to pay for reductions in the risk of death and reduction in the risk of various types of non-fatal injury and disability. In sheer numerical terms, non-fatal injuries far outweigh fatalities in many public sector contexts.

(b) Procedures for evaluating safety effects on future generations. This is clearly a question of central importance for decisions that have very long-term potential consequences such as nuclear power generation and waste disposal.

(c) Experimental work directed at the relationship between subjective and objective probabilities in various contexts. The marginal rates of substitution discussed in this paper, strictly speaking, reflect individual willingness to trade off wealth against subjective perceptions of physical risk. If values of statistical life based on these marginal rates of substitution are to be used in public sector allocative decision making then it is clearly of importance that we know as much as possible about the relationship between these subjective perceptions and their "objective" counterparts.

(d) Investigation of the extent to which more recent theories of choice under uncertainty (proposed to accommodate experimental evidence suggesting frequent violation of the axioms underpinning expected utility theory) entail modification of the theoretical results summarised in Section 3.

(e) Empirical estimates of the cost of safety improvment. Work on the economics of safety has so far concentrated almost exclusively on the benefit side of the problem and relatively little is known about the cost of reducing fatality rates by different amounts. A consequence of this lack of data concerning cost functions is that one has no way of knowing what effect adoption of values of statistical life comparable with those reported in Tables 1 and 2 would have upon overall levels of expenditure on safety. Indeed, some people have speculated that the effects would be so substantial as to be unacceptable. In fact, one suspects that the marginal cost of safety improvement would rise very rapidly beyond some fairly modest level of incremental expenditure of safety so that this, together with falling marginal valuations, would imply only a relatively modest increase in overall expenditure. Preliminary work based on U.S. data ${ }^{23}$ tends to confirm this conjecture but much harder evidence is required if we are to have a clear idea of the impact on overall safety expenditure.

While substantial progress has undoubtedly been made during the last decade, these and many other issues pose questions which are, as yet, essentially unresolved. It is to be hoped that by the end of the next decade, work in this area will have produced not only more reliable empirical estimates of the value of statistical life, but will also have provided answers to at least some of these questions.

\footnotetext{
${ }^{23}$ See Jones-Lee [1984b].
} 


\section{REFERENCES}

ABRAHAM, C. and THEDIÉ, J. [1946]: "Le prix d'une vie humaine dans les décisions économiques", Revue Française de Recherche Opérationnelle.

ACTON, J.P. [1973]: Evaluating Public Programms to Save Lives: The Case of Heart Attacks, Research Report R-73-02, Santa Monica, Rand Corporation.

ACTON, J.P. [1976]: "Measuring the monetary value of life saving programs", Law and Contemporary Problems, 40, 46-72.

AKEHURST, R. and CULYER, A.J. [1974]: "On the economic surplus and the value of life", Bulletin of Economic Research, 64-74.

ARROW, K.J. [1971]: Essays in the Theory of Risk Bearing, Amsterdam, North Holland.

ARTHUR, W.B. [1981]: "The economics of risks to life", American Economic Review, 71, 54-64.

ATIYAH, P.S. [1982]: “A legal perspective on recent contributions to the valuation of life”, in: Jones-Lee [1982], 185-200.

BAILEY, M. J. [1980]: Reducing Risks to Life: Measurement of the Benefits, Washington, American Enterprise Institute.

BERGSTROM,TC. [1974]: "Preferences and choice in matters of life and death", in: Applying Cost-Benefit Concepts to Projects which Alter Human Mortality UCLA-ENG-7478. School of Engineering and Applied Sciences, Los Angeles.

BERGSTROM, TC. [1982]: “Is a man's life worth more than his human capital?”, in: Jones-Lee [1982], 3-26.

BLOMQUIST, G. [1979]: "Value of life saving: implications of consumption activity", Journal of Political Economy, 87, 540-558.

BLOMQUIST, G. [1981]: “The value of human life: an empirical perspective”, Economic Inquiry, 19, 157-164.

BLOMQUIST, G. [1982]: "Estimating the value of life and safety: recent developments", in: Jones-Lee [1982], 27-40.

BODILY, S.E. [1980]: “Analysis of risks to life and limb”, Operations Research, 28, 156-175.

BORCH, K. [1977]: "Optimal life insurance”, The Geneva Papers on Risk and Insurance, 6, 3-16.

BORCH, K. [1978]: "Consumption and saving: models and reality", Theory and Decision, 9, 241-253.

BROOME, J. [1978a]: "Choice and value in economics", Oxford Economic Papers, 30, 313-333.

BROOME, J. [1978b]: "Trying to value a life”, Journal of Public Economics, 9, 91-100.

BROOME, J. [1979]: "Trying to value a life: a reply", Journal of Public Economics, 12, 259-262.

BROOME, J. [1982]: "Uncertainty in welfare economics and the value of life", in Jones-Lee [1982], 201-216.

BROOME, J. [1983a]: “The price of life: where economics is out of its depth",The Financial Times, 17th August.

BROOME, J. [1983b]: Letter to the Editor, The Financial Times, 2nd September.

BROOME, J. [1983c]: "The economic value of life: a problem in the philosophy of population", mimeo, University of Bristol.

BROOME, J. [1984a]: "Uncertainty and fairness”, Economic Journal, 94, 624-632.

BROOME, J.[1984b]: "Selecting people randomly", Ethics, 95, 38-55.

BROWN, C. [1980]: "Equalising differences in the labor market", Quarterly Journal of Economics, 94, $113-134$. 
BROWN, R.A. and GREEN, C.H. [1981]: "Threats to health and safety: perceived risk and willingness-topay", Social Science and Medicine, 15, 67-75.

BUCHANAN, J. and FAITH, R. [1979]: "Trying again to value a life", Journal of Public Economics, $12,245-248$.

CALABRESI, G. and BOLBIT, P. [1978]: Tragic Choices, New York, Norton.

CHASE, S.B. [1968] (Ed): Problems in Public Expenditure Analysis, Washington, Brookings.

CONLEY, B.C. [1976]: "The value of human life in the demand for safety", American Economic Review, 66, 45-55.

CONLEY, B.C. [1978]: "The value of human life in the demand for safety: extension and reply", American Economic Review, 68, 717-719.

COOK, P.J. [1978]: "The value of human life in the demand for safety: comment", American Economic Review, 68, 710-711.

COOK, P.J. and GRAHAM, D.A. [1977]: "The demand for insurance and protection: the case of irreplaceable commodities", Quarterly Journal of Economics, 91, 143-156.

CURRIE, D.A. and PETERS, W. [1980] (Eds): Contemporary Economic Analysis, Vol. 2, London, Croom Helm.

CURRIE, D.A., PEEL, D. and PETERS, W. [1981] (Eds): Microeconomic Analysis, London, Croom Helm.

DARDIS, R. [1980]: "The value of life: new evidence from the market place”, American Economic Review, $70,1077-1082$.

DAWSON, R.F.F. [1967]: Cost of Road Accidents in Great Britain, London, Road Research Laboratory, Ministry of Transport.

DAWSON, R.F.F. [1971] : Current Costs of Road Accidents in Great Britain, London, Road Research Laboratory, Department of the Environment.

DEHEZ, P. and DRĖZE, J.H. [1982]: "State-dependent utility, the demand for insurance and the value of safety", in: Jones-Lee [1982], 41-65.

DILLINGHAM, A.E. [1979]: The Injury Risk Structure of Occupations and Wages, Ph. D. Dissertation, Cornell University.

DILLINGHAM, A.E. [1980]: "The relationship between estimates of wage premiums for injury risk and the measurement of injury risk: results from one population”, Illinois State University, Department of Economics.

DOBBS, I.M. [1985]: "Shadow prices, consistency and the value of life", Journal of Public Economics, forthcoming.

DORFMAN, R. [1965] (Ed): Measuring Benefits of Government Investments, Washington, Brookings.

DORSEY, S. and WALZER, N. [1983]: "Workers' compensation, job hazards and wages", Industrial and Labor Relations Review, 36, 642-654.

DRÈZE, J.H. [1962]: "L'utilité sociale d'une vie humaine", Revue Française de Recherche Opérationnelle.

DUBLIN, C.I. and LOTKA, A.J. [1930]: The Money Value of a Man, New York, Ronald Press.

DUVAL, H. [1979]: "Essai sur la valeur de la vie et la valeur du temps", Organisme National de Sécurité Routière, Arcueil.

DUVAL, H. [1983]: "La valeur monétaire d'une vie humaine", Cahiers d'Etudes de L'Organisme National de Sécurité Routière, Arcueil.

EISNER and STROTZ, R.H. [1961]: "Flight insurance and the theory of choice", Journal of Political Economy, 69, 355-368.

ENGEL, E. [1893]: "Der Werth des Menschen”, Volkswirtschafliche Zeitfragen.

FARR, W. [1876]: Contribution to 39th Annual Report of the Registrar General of Births, Marriages and Deaths for England and Wales. 
FISCHER, G.W. and VAUPEL, J.W. [1976]: "A lifespan utility model: assessing preferences for consumption and longevity", Working Paper, Durham, N.C.: Center for Policy Analysis, Institute of Policy Sciences and Public Affairs, Duke University.

FRANK, R.H. [1982]: "Envy and the optimal purchase of unobservable commodities : the case of safety", in: Jones-Lee [1982], 145-157.

FRANKEL, M. [1979]: "Hazard opportunity and the valuation of life", mimeo, University of Illinois at Urbana-Champaign.

FRASER, C.D. [1980]: "Optimal compensating insurance, informational asymmetries and government discretionary behaviour", mimeo, University of York.

FRASER, C.D. [1984]: "Optimal compensation for potential fatality", Journal of Public Economics, 23, 307-332.

FREEMAN, A.M. [1979]: "The benefits of environmental improvement", Baltimore, Johns Hopkins University Press.

FRIED, C. [1969]: "The value of human life", Harvard Law Review, 82, 1415-1437.

FRIEDMAN, D. [1982] : "What is fair compensation for death or injury?", International Review of Law and Economics, 2, 81-93.

FROMM, G. [1965]: "Civil aviation expenditures”, in: Dorfman [1965].

GHOSH, D., LEES, D. and SEAL, W. [1975]: "Optimal motorway speed and some valuations of time and life", Manchester School, 43, 134-143.

GLOVER, J. [1977]: Causing Death and Saving Lives, Harmondsworth, Penguin Books.

GLOVER, J. [1978]: "Assessing the value of saving lives", in : Vesey [1978], 208-227.

GOULD, W. and THALER, R. [1980]: "Public policy toward life saving: maximise lives saved vs. consumer sovereignty", Cambridge, Mass. NBER Working Paper Series.

GRAVELLE, H.S.E. [1979]: "The value of changes in individual risk in a large mixed economy", Economics Letters, 3, 145-148.

GREENE, G. [1980]: Dr. Fischer of Geneva or the Bomb Party, London, The Bodley Head.

HAMMERTON, M., JONES-LEE, M.W. and ABBOTT, V. [1982]: "The consistency and coherence of attitudes to physical risk", Journal of Transport Economics and Policy, 16, 181-199.

HAMMERTON, M., JONES-LEE, M.W. and ABBOTT, V. [1982]: "Equity and public risk: some empirical results", Operations Research, 30, 203-207.

HAMMOND, P.J. [1982]: "Utilitarianism, uncertainty and information", in: Sen and Williams [1982], 85-102.

HARSANYI, J.C. [1955]: "Cardinal welfare, individualistic ethics and interpersonal comparisons of utility", Journal of Political Economy, 83, 309-321.

HILLS, P.J. and JONES-LEE, M.W. [1983]: "The role of safety in highway investment appraisal for developing countries", Accident Analysis and Prevention, 15, 355-369.

HOCKLEY, G.C. [1983]: Letter to the Editor, Financial Times, 2nd September.

JACOBS, J.D. and SAYER, I. [1983]: "Road accidents in developing countries", Accident Analysis and Prevention, 15, 337-353.

JONES, G.H. [1946]: Road Accidents, Report submitted to the Minister of Transport, London, H.M.S.O.

JONES-LEE, M.W. [1969]: "Valuation of reduction in probability of death by road accident", Journal of Transport Economics and Policy, 3, 37-47.

JONES-LEE, M.W. [1974]: "The value of changes in the probability of death or injury", Journal of Political Economy, 82, 835-849.

JONES-LEE, M.W. [1975]: “Optimal life insurance: comment”, Journal of Finance, 30, 902-903.

JONES-LEE, M.W. [1976]: The Value of Life: An Economic Analysis, London, Martin Robertson and Chicago, The University of Chicago Press. 
JONES-LEE, M.W. [1978]: "The value of human life in the demand for safety: comment", American Economic Review, 68, 712-716.

JONES-LEE, M.W. [1979]: “Trying to value a life: why Broome does not sweep clean”, Journal of Public Economics, 12, 249-256.

JONES-LEE, M.W. [1980a]: "Human capital, risk aversion and the value of life", in: Currie and Peters [1980].

JONES-LEE, M.W. [1980b]: "Maximum acceptable physical risk and a new measure of financial risk aversion", Economic Journal, 90, 550-568.

JONES-LEE, M.W. [1981]: “The value of non-marginal changes in physical risk", in: Currie, Peel and Peters [1981], 233-268.

JONES-LEE, M.W. and PONCELET, A.M. [1982] : "The value of marginal and non-marginal multiperiod variations in physical risk", in: Jones-Lee [1982], 67-80.

JONES-LEE, M.W. [1982](Ed): The Value of Life and Safety: Proceedings of a Conference Held by the Geneva Association, Amsterdam, North Holland.

JONES-LEE, M.W., HAMMERTON, M. and ABBOTT, V. [1983]: The Value ofTransport Safety: Results of a National Sample Survey, Report to the U.K. Department of Transport.

JONES-LEE, M.W. [1983]: Letter to the Editor, Financial Times, 22nd August.

JONES-LEE, M.W. [1984a]: "Natural disasters: a comparison of alternative methods for evaluating preventive measures", The Geneva Papers on Risk and Insurance, 9, 188-205.

JONES-LEE, M.W. [1984b]: "The valuation of transport safety", in: Proceedings of the AnnualTransportation Convention, Pretoria, 1984, Vol. G, pp. 1-14.

JONES-LEE, M.W., HAMMERTON, M. and PHILIPS, P.R. [1985]: "The value of safety: results of a national sample survey", Economic Journal, 95, 49-72.

KEENEY, R.L. [1980a]: "Evaluating alternatives involving potential fatalities", Operations Research, 28, 188-205.

KEENEY, R.L. [1980b]: "Equity and public risk", Operations research, 28, 527-534.

KEENEY, R.L. [1980c]: "Utility functions for equity and public risk", Management Science, 26, 345-353.

KEENEY, R.L. [1982]: "Evaluating mortality risks from an organisational perspective”, in: Jones-Lee [1982], 217-227.

KIND, P., ROSSER, R. and WILLIAMS, A. [1982]: "Valuation of quality of life : some psychometric evidence", in: Jones-Lee [1982], 159-170.

LE NET, M. [1978]: Le Prix de la Vie Humaine, Paris, La Documentation Française.

LINNEROOTH, J. [1976]: “Methods for evaluating mortality risk", Futures, 8, 293-304.

LINNEROOTH, J. [1979]: “The value of human life: a review of the models", Economic Inquiry, 17, 52-74.

LINNEROOTH, J. [1982]: “Murdering statistical lives...?”, in: Jones-Lee [1982], 229-261.

LEITCH, G. [1977]: Report of the Advisory Committee on Trunk Road Assessement, London, H.M.S.O.

LUDTKE, R. [1873]: Contribution to: Deutsche Versicherungs-Zeitung.

MACLEAN, A.D. [1979]: The Value of Public Safety: Results of a Pilot-Scale Survey, London, Home Office Scientific Advisory Branch.

MARIN, A. [1983]: "Your money or your life", The Three Banks Review, 138, 2-37.

MARIN, A. [1983]: Letter to the Editor, Financial Times, 23rd August.

MARIN, A. and PSACHAROPOULOS, G. [1982]: "The reward for risk in the labor market: evidence from the United Kingdom and a reconciliation with other studies", Journal of Political Economy, 90, 827-853.

MARSHALL, J.M. [1984]: "Gambles and the shadow price of death", American Economic Review, 74, 73-86. 
MAVROMAROS, K. [1979]: "Insurance and protection of irreplaceable commodities: the case of one's own life", Economics Letters, 3, 9-13.

MELINEK, S.J. [1974]: “A method of evaluating human life for economic purposes”,Accident Analysis and Prevention, 6, 103-114.

MELINEK, S.J., WOOLLEY, S.K.D. and BALDWIN, R. [1973]: Analysis of a Questionnaire on Attitudes to Risk, Borehamwood, Joint Fire Research Organisation Fire Research Note 962.

MISHAN, E.J. [1971]: "Evaluation of life and limb:a theoretical approach", Journal of Political Economy, $79,687-705$.

MISHAN, E.J. [1981]: “The value of trying to value a life”, Journal of Public Economics, 15, 133-137.

MISHAN, E.J. [1982]: "Recent contributions to the litterature of life valuation: a critical assessement", in: Jones-Lee [1982], 81-92.

MOONEY, G. [1977]: The Valuation of Human Life, New York, Macmillan Press.

MULLIGAN, P.J. [1977]: "Willingness to pay for decreased risk from nuclear plant accidents", Working Paper No. 3, Energy Extension Programs, Pennsylvania State University.

NATIONAL RADIOLOGICAL PROTECTION BOARD [1980]: The Application of Cost Benefit Analysis to the Radiological Protection of the Public: A Consultative Document, Chilton, H.M.S.O.

NATIONAL RADIOLOGICAL PROTECTION BOARD [1982]: Cost Benefit Analysis in the Optimisation of Protection of Radiation Workers: A Consultative Document, Chilton, N.R.P.B.

NEEDLEMAN, L. [1976]: “Valuing other people's lives”, Manchester School, 44, 309-342.

NEEDLEMAN, L. [1980]: "The valuation of changes in the risk of death by those at risk", Manchester School, 48, 229-254.

NEEDLEMAN, L. [1982]: "Survival discount rates", mimeo, University of Waterloo.

NEILSON, A.M. [1983]: Methods of Valuing Human Life, Wellington, National Roads Board.

O.E.C.D. [1981]: Methods for Evaluating Road Safety Measures, Paris, O.E.C.D.

OLSON, C. [1978]:Trade Unions, Wages, Occupational Injuries and Public Policy, Ph.D. Dissertation, University of Wisconsin.

PETTY, W. [1699]: Political Arithmetik, or a Discourse Concerning the Extent and Value of Lands, People, Buildings etc., London, Robert Clavel.

PRESCOTT-CLARKE, P. [1982]: Public Attitudes Towards Industrial, Work-Related and Other Risks, London, S.C.P.R.

PORTNEY, P.R. [1981] : "Housing prices, health effects and valuing reductions in risk of death", Journal of Environmental Economics and Management, 8, 72-78.

PLISKIN, J.S., SHEPARD, D.S. and WEINSTEIN, M.C. [1980]: "Utility functions for life years and health status", Operations Research, 28, 206-224.

RAIFFA, H. [1969]: Preferences for Multi-Attributed Alternatives, Research Memorandum 5858M, Department of Transportation, Washington.

REYNOLDS, D.J. [1956]: “The cost of road accidents”, Journal of the Royal Statistical Society, 119, 398-408.

ROSEN, S. [1981]: "Valuing health risk", American Economic Review, 71, 241-245.

ROTHMAN, M.A. [1980]: “Death risk”, Analog, 40-53.

LORD ROTHSCHILD [1978]: Risk (The Richard Dimbleby Lecture, November 1978), London, B.B.C.

SAVAGE, L.J. [1954]: The Foundations of Statistics, New York, Wiley.

SCHELLING, T.C. [1968]: "The life you save may be your own" in: Chase (1968), 127-176.

SEN, A. and WILLIAMS, B. [1982]: Utilitarianism and Beyond, Cambridge, Cambridge University Press. 
SHEPARD, D.S., PLISKIN, J.S. and WEINSTEIN, M.C. [1975]: "The non-existence of reduced form utility functions: problems in valuing lotteries on length of life", mimeo, Boston, Center for the Analysis of Health Practices, Harvard School of Public Health.

SHEPARD, D.S. and ZECKHAUSER, R. [1982]: "Life-cycle consumption and willingness to pay for increased survival", in: Jones-Lee [1982], 95-141.

SILCOCK, D.T. [1982]: "Traffic accidents: procedures adopted in various countries for estimating their costs or valuing their prevention", Transport Reviews, 2, 79-106.

SMITH, R.S. [1973]: “Compensating wage differentials and hazardous work”, Technical Paper No. 5, Office of Policy Evaluation and Research, Department of Labor.

SMITH, R.S. [1976]: The Occupational Safety and Health Act: Its Goals and Its Achievements, Washington, American Enterprise Institute.

SMITH, R.S. [1979]: "Compensating wage differentials and public policy : a review", Industrial and Labor Relations Review, 32, 339-352.

SUGDEN, R. and WILLIAMS, A. [1978]: The Principles of Practical Cost-Benefit Analysis, Oxford, Oxford University Press.

SUSSMAN, F.G. [1984]: "A note on the willingness to pay approach to the valuation of longevity", Journal of Environmental Economics and Management, 11, 84-89.

TERLECKYJ, N.E. [1976] (Ed): Household Production and Consumption, New York, N.B.E.R.

THALER, R. [1982]: "Precommitment and the value of life", in: Jones-Lee [1982], 171-183.

THALER, R. and ROSEN, S. [1973]: "The value of saving a life : evidence from the labor market", University of Rochester Graduate School of Management Working Paper No. 7401. Also in Terleckyj [1976], 265-301.

TROY, P.N. and BUTLIN, N.G. [1971]: The Cost of Collisions, Melbourne, F.W. Cheshire Publishing Pty. Ltd.

ULPH, A. [1982]: "The role of ex ante and ex post decisions in the valuation of life", Journal of Public Economics, 18, 265-276.

USHER, D. [1973]: "An imputation to the measure of economic growth for changes in life expectancy", Conference on Research in Income and Wealth, New York, N.B.E.R.

VAUPEL, J.W. [1976]: "Early death: an american tragedy", Law and Contemporary Problems, 40, 73-121.

VELJANOVSKI, C. [1978]: "The economics of job safety regulation: theory and evidence: part I - the market and common law", mimeo, Oxford, Centre for Socio-Legal Studies.

VESEY, G. [1978]: Human Values, Brighton, Harvester Press.

VISCUSI, W.K. [1978] : "Labor market valuations of life and limb: empirical evidence and policy implications", Public Policy, 26, 359-386.

VISCUSI, W.K. [1980]: "Imperfect job risk information and optimal workmen's compensation benefits", Journal of Public Economics, 14, 319-337.

VON NEUMANN, J, and MORGENSTERN, O. [1947]: Theory of Games and Economic Behavior, Princeton, Princeton University Press.

WARNER, F. [1981] (Ed): The Assessment and Perception of Risk, London, The Royal Society.

WEINSTEIN, M.C., SHEPARD, D.S. and PLISKIN, J.S. [1980]: "The economic value of changing mortality probabilities: a decision-theoretic approach", Quarterly Journal of Economics, 94, 373-396.

WILLIAMS, A. [1979]: “A note on trying to value a life”, Journal of Public Economics, 12, 257-258.

WILLIAMSON, J.G. [1982]: "British mortality and the value of life 178I-193I", mimeo, University of Wisconsin. 
WOODS, E.A. and METZGER, C.B. [1927]: America's Human Wealth: The Money Value of a Human Life, New York, Kelly.

YAARI, M.E. [1965]: "Uncertain lifetime, life insurance and the theory of the consumer", Review of Economic Studies, 32, 137-150.

ZECKHAUSER, R. [1975]: "Procedures for valuing lives", Public Policy, 23, 419-464.

ZECKHAUSER, R. and SHEPARD, D. [1976]: "Where now for saving lives?", Law and Contemporary Problems, 40, 5-45. 